\title{
Trajetória docente e a formação de terapeutas ocupacionais para atenção primária à saúde
}

Rodrigo Alves dos Santos Silva(a)

Fátima Corrêa Oliver(b)

Silva RAS, Oliver FC. Teaching career path and training of occupational therapists to primary health care. Interface (Botucatu). 2017; 21(62):661-73.

This study aimed to identify and analyze the teaching career path and training of occupational therapists for Primary Health Care (PHC) in the state of São Paulo, Brazil. It is a qualitative research through interviews with 17 occupational therapy teachers. Data were categorized into two topics. 1) Teaching career path identified with $\mathrm{PHC}$ due to training experiences, professional practice and desires of changes to the clinical possibilities of territorial and extra-mural action and community occupational therapy. 2) The teachers reported training for PHC in courses through different teaching strategies, research and extension. Teaching career path in $\mathrm{PHC}$ and practicetheoretical learning needs to be valued in the training of occupational therapists acting in $\mathrm{PHC}$.

Keywords: Occupational therapy. Training of health professionals. Work in health. Primary health care. Brazilian National Health System.
Objetivou-se identificar e analisar a trajetória docente e a formação de terapeutas ocupacionais para Atenção Primária à Saúde (APS) no estado de São Paulo, Brasil. Pesquisa de abordagem qualitativa por meio da realização de entrevistas com 17 docentes de terapia ocupacional. Os dados foram categorizados em dois temas. 1) A trajetória docente foi identificada com a APS a partir de experiências de formação, de prática profissional e de anseios de mudanças para as possibilidades extramuros de atuação territorial e comunitária da terapia ocupacional. 2) As docentes apontaram a realização da formação para APS nos cursos por meio de diferentes estratégias de ensino, pesquisa e extensão. A trajetória docente na APS e a aprendizagem teóricoprática deve ser valorizada na formação de terapeutas ocupacionais para APS.

Palavras-chave: Terapia ocupacional. Formação de profissionais de saúde. Trabalho em saúde. Atenção primária à saúde. Sistema Único de Saúde.

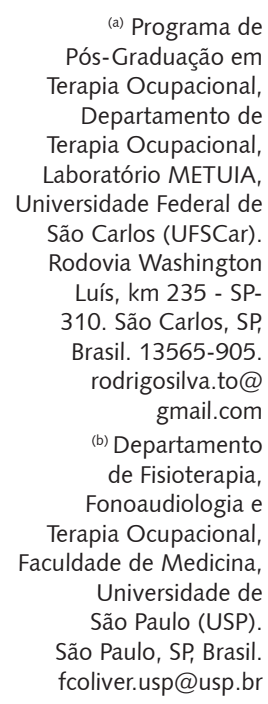

(a) Programa de Pós-Graduação em Terapia Ocupacional, Departamento de Terapia Ocupacional Laboratório METUIA, Universidade Federal de São Carlos (UFSCar). Rodovia Washington Luís, km 235 - SP-

310. São Carlos, SP

Brasil. 13565-905. rodrigosilva.to@ gmail.com

(b) Departamento de Fisioterapia, Fonoaudiologia e Terapia Ocupacional, Faculdade de Medicina, Universidade de São Paulo (USP). São Paulo, SP, Brasil. fcoliver.usp@usp.br 


\section{Introdução}

A formação de terapeutas ocupacionais para a Atenção Primária à Saúde (APS) no Brasil se desenvolve a partir dos anos 1980 e 1990, quando se inicia a abrangência da formação para o cuidado nos três níveis de atenção à saúde, por meio da publicação do Currículo Mínimo de Terapia Ocupacional de $1983^{1}$. Esse documento alargou a formação dos profissionais de terapia ocupacional para além da reabilitação, ao contemplar as ações de prevenção de doenças e agravos e de promoção da saúde².

Nesse contexto, tal mudança de perspectiva na formação de terapeutas ocupacionais se desenvolveu, sobretudo, devido à participação de docentes e profissionais da área, em processos de luta por cuidado integral, como nas Reformas Sanitária e Psiquiátrica brasileiras e pela luta e conquista de um sistema de saúde público para todos ${ }^{3}$.

Esse marco da formação em 1983 e a participação de terapeutas ocupacionais nos processos de luta e mobilização social por direitos políticos, sociais e humanos do público-alvo de suas ações, somou-se à trajetória de capacitação de docentes para o desenvolvimento de pesquisas em diferentes áreas do conhecimento, como: saúde coletiva, educação, psicologia, educação especial e ciências sociais $^{4}$. Esse processo vem sendo fortalecido com a recente criação de programa de pós-graduação stricto sensu em terapia ocupacional na Universidade Federal de São Carlos.

Um outro marco importante nesse cenário foi a publicação das Diretrizes Curriculares Nacionais de Terapia Ocupacional de $2002^{5}$ e as Políticas de formação de profissionais de saúde para o SUS (como o Pró-Saúde, Pet-Saúde, Ver-SUS, residências multiprofissionais), que apontam para a necessidade de uma formação geral e específica de profissionais para serem aptos a trabalharem de maneira interprofissional no contexto do SUS, a partir das realidades locais, em serviços de diferentes níveis de atenção, tanto de APS como nos serviços especializados ${ }^{6}$.

Diante das transformações no campo da formação de terapeutas ocupacionais, são necessários esforços desse campo profissional para se refletir sobre a trajetória docente e a formação que é realizada nos cursos públicos e privados de terapia ocupacional para a APS, a fim de atender a inserção e o trabalho desse profissional nesse âmbito assistencial; como, também, às necessidades de pessoas que se encontram prejudicadas em sua inserção e participação social e na realização das suas atividades cotidianas ${ }^{6,7}$.

Desse modo, o objetivo deste artigo foi identificar e analisar a trajetória docente e a formação de terapeutas ocupacionais para APS no estado de São Paulo.

\section{Percurso metodológico}

O presente estudo caracteriza-se como de abordagem qualitativa. Fruto da pesquisa de mestrado sobre a 'Formação Graduada de Terapeutas Ocupacionais para o Cuidado na APS no Estado de São Paulo'. Foi realizada a análise das múltiplas realidades subjetivas produzidas pelas trajetórias e experiências das participantes docentes na formação de terapeutas ocupacionais para a APS ${ }^{8}$.

A pesquisa teve como recorte empírico os cursos localizados no estado São Paulo, que possui o maior número de cursos do país: 14 cursos de terapia ocupacional, cinco cursos públicos e nove cursos privados, de um total de 43 cursos públicos e privados em funcionamento no Brasil, no ano de 2015. O estado de São Paulo também possui o curso público mais antigo do Brasil, em funcionamento desde o ano de $1956^{9,10 .}$

De maneira a promover e contribuir para o debate sobre a formação em saúde e de terapeutas ocupacionais para a APS, realizamos a análise da trajetória de 17 docentes de cinco cursos públicos e quatro privados de terapia ocupacional do estado de São Paulo, que são responsáveis pela formação de terapeutas ocupacionais para APS nesses cursos.

Assim, para a construção dos dados, foi utilizado como instrumento de pesquisa: o Roteiro de Entrevista com Docente responsável pela formação para a APS, previamente construído com a contribuição de sete especialistas que possuem experiências no campo da pesquisa, ensino e prática profissional, relacionados aos campos da APS. 
O critério de escolha dos participantes foi intencional, a partir de autorização de participação na pesquisa de nove cursos de terapia ocupacional de um total de 14 que estavam em funcionamento no estado de São Paulo no ano de 2015. Nesse sentido, atendendo a indicação de cada coordenador dos nove cursos, chegamos a 17 docentes, que realizam a formação de terapeutas ocupacionais para APS.

O processo de coleta dos dados foi realizado nas instituições de ensino dos participantes da pesquisa. Assim, após a leitura e assinatura do Termo de Consentimento Livre e Esclarecido (TCLE), foram registradas, em gravador de áudio, 17 entrevistas com as docentes, com duração total de 11 horas e 26 minutos, que foram transcritas, revisadas, organizadas e armazenadas em banco de dados. As transcrições foram encaminhadas às participantes via correio eletrônico a fim de possibilitar a análise de seus conteúdos e, se necessário, modificar algo que se julgasse pertinente. Apenas duas docentes recomendaram mudanças na transcrição, mas não houve alterações significativas que prejudicassem o conteúdo das falas iniciais.

A partir do banco de dados criado, foi realizada a leitura exaustiva, o tratamento do material construído em campo e a categorização de temas associados ao objetivo do estudo. Para essa pesquisa, foi utilizado o processo de categorização, onde os dados construídos foram fornecidos ao sistema de categorias à medida que iam sendo encontradas ${ }^{11}$.

Para este artigo, foram escolhidas as seguintes categorias: a trajetória de formação profissional e acadêmica das docentes terapeutas ocupacionais na APS; as atividades de formação nos campos do ensino, pesquisa e extensão, e as metodologias de ensino-aprendizagem.

Os dados construídos foram analisados à luz das Diretrizes Curriculares Nacionais do Curso de Graduação em Terapia Ocupacional ${ }^{5}$ e dos referenciais teóricos e metodológicos da terapia ocupacional e da Saúde Coletiva, além das pesquisas e evidências científicas produzidas no campo da formação em saúde e em terapia ocupacional.

A pesquisa foi submetida ao Comitê de Ética em Pesquisa da Universidade Federal de São Carlos (CEP/UFSCar), em conformidade com os princípios da Resolução 466/2012 ${ }^{12}$ e parecer favorável a sua realização.

\section{Resultados e discussão}

\section{A trajetória de formação profissional e acadêmica das docentes terapeutas ocupacionais na APS}

As trajetórias com a APS das 17 docentes participantes dessa pesquisa possibilitaram reconhecer seus percursos de formação, tendo como eixo estruturante a criação do SUS em 1990. Conforme demonstrado no Quadro 1, sete docentes cursaram terapia ocupacional antes do SUS e dez docentes após esse marco legal para o cuidado à saúde no Brasil.

\section{Graduação em Terapia Ocupacional antes do SUS}

A formação graduada em terapia ocupacional dos anos 1970 e 1980 foi marcada pelas reivindicações de mudanças no caráter formativo de uma profissão eminentemente técnica para uma formação humanística, técnica, política, e que tinha como necessidade o desenvolvimento do campo de conhecimento próprio para responder às necessidades da população ${ }^{1}$.

Como fruto dessas reivindicações, em 1983, instituiu-se o Currículo Mínimo para os cursos de graduação de terapia ocupacional. Esse currículo propôs inúmeras transformações, com destaque para a mudança na formação de um modelo clínico-biológico para um modelo de saúde, que integrasse o enfoque psicológico e social ao biológico ${ }^{1}$.

Diante desse contexto de transformação, na trajetória de graduação em terapia ocupacional das docentes antes do SUS, observamos, nos excertos das entrevistas, as 'diferentes estratégias' que as levaram a ter a formação para a APS. 
Quadro 1. Caracterização das docentes

\begin{tabular}{|c|c|c|c|}
\hline Participantes & \multirow{2}{*}{$\begin{array}{l}\text { Ano de } \\
\text { Formação } \\
\text { em TO }\end{array}$} & \multirow{2}{*}{ Pós-Graduação de maior nível } & \multirow{2}{*}{$\begin{array}{c}\text { Tempo na IES e tempo } \\
\text { vinculado a formação } \\
\text { para APS }\end{array}$} \\
\hline Graduação Antes do SUS & & & \\
\hline Docente 6 & 1979 & Doutorado em Psicologia Social - 1999 & 31 anos/ 16 anos \\
\hline Docente 17 & 1980 & Doutorado em Medicina (Saúde Mental) - 2000 & 13 anos/13 anos \\
\hline Docente 15 & 1981 & Doutorado em Filosofia da Educação - 2012 & 17 anos/10 anos \\
\hline Docente 8 & 1983 & Doutorado em Engenharia de Produção - 2004 & 10 anos/8 anos \\
\hline Docente 7 & 1985 & Doutorado em Saúde Coletiva - 2000 & 29 anos/29 anos \\
\hline Docente 2 & 1986 & Doutorado em Psicologia - 2009 & 5 anos/5 anos \\
\hline Docente 1 & 1988 & Doutorado em Medicina Preventiva - 2012 & 1 ano/8 meses \\
\hline \multicolumn{4}{|l|}{ Graduação pós SUS } \\
\hline Docente 5 & 1997 & Doutorado em Saúde Coletiva - 2014 & 1 mês/ 1 mês \\
\hline Docente 3 & 1999 & Doutorado em Saúde Coletiva - 2013 & 8 meses/8 meses \\
\hline Docente 4 & 2001 & Doutorado em Saúde Pública - 2008 & 10 anos/10 anos \\
\hline Docente 9 & 2001 & Doutorado em Educação - 2013 & 2 anos/2 anos \\
\hline Docente 14 & 2002 & Mestre em Psicologia da Saúde - 2011 & 2 anos e 6 meses/ 1 ano \\
\hline Docente 12 & 2002 & $\begin{array}{l}\text { Esp. em Administração de Recursos Humanos - } \\
2008\end{array}$ & 7 anos $/ 6$ meses \\
\hline Docente 11 & 2005 & Especialista em Docência do Ensino Superior - 2009 & 6 anos/3 anos \\
\hline Docente 13 & 2007 & Especialista em Tecnologia Assistiva - 2012 & 3 anos/3 anos \\
\hline Docente 10 & 2008 & Doutorado em Educação Especial - 2015 & 1 ano e 6 meses/ 6 meses \\
\hline Docente 16 & 2010 & Mestre em Saúde Pública - 2013 & 1 ano/6 meses \\
\hline
\end{tabular}

“Em relação à trajetória da minha formação de [1976-1979] para APS: eu não tive. O que eu tive foram experiências de movimento estudantil. Nós fazíamos discussões sobre a questão da assistência à população na rede pública, íamos na periferia conhecer o que era um centro de saúde [...] Na época, ficava a dúvida o que um terapeuta ocupacional faz junto à população no centro de saúde [...] O que ficou disso? Ficou que: quando você está na comunidade, quando você está no território, quando você está perto da população, os problemas aparecem de um jeito diferente do que aquele de quando você está no hospital ou em uma instituição especializada [...]". (Docente 6)

"Olha, eu acho que eu vivi em um período da minha graduação [início dos anos 1980] que nós elaborávamos muito criticamente a própria formação que recebíamos [...] Eu não tive nenhuma aproximação com essa temática [da APS]. Pelo menos não formalmente. Eu me lembro que nos encontros de estudantes que naquela época se chamava Encontro Nacional dos Universitários de Reabilitação (ENUR), tivemos contato com a questão muito fortemente associada entre a atenção básica e a prevenção [...]" (Docente 7)

“Me formei entre [1983-1986], a única possibilidade de relacionamento com essa área [da APS] foi em um estágio [bem curto] em UBS [...] Participei um pouco junto com os delegados que foram para Brasília para a 8 a Conferência de Saúde de 1986 [...]". (Docente 2)

“Eu me formei em 1980, não tínhamos nem a constituição de 1988. Eu tive práticas, não com o nome de atenção primária, mas foram práticas com a perspectiva de atenção primária, em creches para a promoção da saúde com as crianças [...] eu fui também para presídios, para zonas de prostituição para promover a saúde [...]". (Docente 17) 
As docentes tiveram aproximação com o campo da APS a partir de suas experiências e de seus anseios de mudanças para as possibilidades extramuros de atuação territorial e comunitária da terapia ocupacional, e reconheciam a APS como um possível cenário de atuação. Essas experiências perpassaram, também, a participação nas prévias para a realização da $8^{\text {a }}$ Conferência Nacional de Saúde e nas discussões do movimento estudantil e dos movimentos sociais, tanto na perspectiva de redemocratização do país como pela conquista de direitos para populações vulneráveis.

Nas trajetórias docentes, havia, também, uma inquietação sob a questão social no país, como observamos nessa fala:

\begin{abstract}
“Não discutíamos Atenção Primária [na minha formação inicial], mas desde o meu primeiro ano do curso, eu fui convidada para participar de uma atividade que se chamava Oficina de Brinquedos e essa oficina era um pouco dessa possibilidade de pensar, no território, quais eram as crianças que estavam vivendo em uma situação de vulnerabilidade ou de risco social. Então era uma questão não necessariamente de Atenção Primária à Saúde, mas era uma questão de já pensar a questão social [...]". (Docente 15)
\end{abstract}

Algumas docentes apontaram uma reflexão crítica quanto à questão social na saúde a partir das contribuições da Saúde Coletiva, como campo de conhecimentos, pesquisa e de práticas, que permitia, em parte, às docentes terapeutas ocupacionais, alargarem o escopo da profissão para além de um modelo clínico-biológico¹.

\title{
Graduação em terapia ocupacional pós-SUS
}

As docentes que representam o grupo de trajetória de formação em terapia ocupacional pósSUS, tiveram a finalização da sua graduação a partir de 1997; nessa época, já tínhamos a Estratégia de Saúde da Família, seu financiamento e as diretrizes estruturadas por meio da Norma Operacional Básica - NOB/1996. Em relação ao cuidado em saúde na APS, o Brasil encontrava-se na fase de descentralização dos serviços.

Quanto à Educação Superior e à graduação de terapeutas ocupacionais, essas docentes vivenciaram as mudanças promovidas pela Lei de Diretrizes e Bases da Educação Nacional (LDB/1996) ${ }^{13}$ e pelas discussões e formulação das Diretrizes Curriculares Nacionais de Terapia Ocupacional em $2002^{5}$. Além da organização docente via a Rede Nacional de Ensino e Pesquisa em Terapia Ocupacional (RENETO).

A aproximação dessas docentes aos conteúdos da APS ocorreu por meio de disciplinas como: Saúde Pública, Saúde Coletiva ou Saúde Mental, como podemos ver na descrição das docentes sobre suas 'Trajetórias na Graduação':

“Esse tema [APS] foi abordado na minha formação diluída em outras disciplinas, como em noções de saúde pública [...]". (Docente 5)

“Eu tive algumas disciplinas que passavam pelo campo transversal da Atenção Primária, que tinha uma perspectiva da saúde mental [...] muito aplicada a Atenção Primária eu tive a disciplina de saúde coletiva [...]". (Docente 16)

“Durante a minha formação eu tive a disciplina de saúde pública [única que discutiu APS], então eu aprendi basicamente os princípios do SUS, as leis que regem, as principais ações que realiza[...]". (Docente 10)

Outro aspecto que permitiu a aproximação das docentes com a APS foi a realização de estágios no contexto territorial e comunitário, seja em Unidade Básica de Saúde (UBS), centros comunitários ou em Unidades de Saúde da Família. 
“Durante a minha formação eu não tive uma disciplina relacionada à APS, mas ao longo dos estágios [no centro comunitário] mais especificamente, foi quando eu tive maior experiência com atenção primária [...]". (Docente 14)

“[...] Um dos meus estágios foi em uma UBS, inclusive estávamos começando a pensar o serviço de Terapia Ocupacional dentro dessa UBS e, de uma maneira muito particular, pensando no modo como as pessoas faziam uso daquele serviço, então fazíamos grupos, íamos nos inserindo em alguns grupos que a Enfermagem já fazia [...]". (Docente 12)

Essas experiências na graduação já traziam a utilização de ferramentas importantes para terapia ocupacional na APS, como a estratégia de acompanhamento em grupo sendo utilizada fora das instituições tradicionais em que a terapia ocupacional atuava como centros de reabilitação, instituições filantrópicas e serviços de saúde mental.

O conhecimento e o manejo do trabalho com grupos são essenciais na formação e no trabalho do terapeuta ocupacional na APS, por ser esse um potente instrumento de experimentação de convivência social e para promover, por meio de coletivos afetivamente significativos, ações de educação em saúde, de circulação e participação das pessoas de forma mais ativa em suas comunidades ${ }^{14}$.

Outra contribuição importante para a formação do terapeuta ocupacional na APS, segundo as docentes, foi a Reabilitação Baseada na Comunidade (RBC). Como podemos notar nas seguintes falas:

“[...] Eu fiz estágio de disfunção física com enfoque em RBC, que tinha como uma das frentes de atuação uma unidade de saúde [...] estágio voltado principalmente à atenção de pessoas com deficiência física[...]". (Docente 4)

“Eu participei de um estágio supervisionado, que era Reabilitação Baseada na Comunidade. Eu tenho certeza que muito do que eu aprendi [na graduação], eu acabo utilizando com os alunos [...]". (Docente 13)

A RBC pode contribuir para a formação de terapeutas ocupacionais na APS à medida que consiga, a partir da reflexão crítica sobre as práticas convencionais de reabilitação, sensibilizar o fazer do desenvolvimento e de participação comunitária, construindo um olhar diferenciado sobre a deficiência, as incapacidades e as desvantagens sociais vividas por pessoas em seu contexto social e cultural ${ }^{15,16}$.

\section{Trajetórias das docentes na prática profissional}

Mesmo que o estado de São Paulo tenha tido diferentes movimentos em relação à implantação de serviços da APS. De uma maneira específica, a cidade de São Paulo iniciou tardiamente a municipalização dos serviços de saúde, somente a partir da gestão de Marta Suplicy, em 2001. Tal situação decorre porque a construção do SUS, iniciada na gestão municipal de Luiza Erundina (entre 1989-1992), fora abortada pela contradição sanitária, o Plano de Atendimento à Saúde (PAS), de Paulo Maluf e Celso Pitta17.

$\mathrm{Na}$ cidade de São Paulo, no início dos anos 2000, começaram os projetos de Qualidade Integral à Saúde (Qualis/PSF) vinculados à Fundação Zerbini e ao Hospital Santa Marcelina. O projeto Qualis/ PSF da Fundação Zerbini, liderado pelo importante sanitarista David Capistrano Filho, desenvolveu iniciativas de renovação do sistema de saúde por meio do reconhecimento das necessidades, da participação popular e da formação de conselhos locais de saúde ${ }^{17}$.

Cabe destacar a aproximação das trajetórias das terapeutas ocupacionais docentes com a APS, já na gestão de Luiza Erundina e, depois, junto ao projeto Qualis/PSF, seja por meio da prática profissional ou da pesquisa, como relatam as docentes:

"Quando eu fui fazer o mestrado, era o início da implementação, na época, do Programa de Saúde da Família no estado de São Paulo. Então o início ali dos anos 2000, eram as primeiras 
equipes sendo implementadas e eu fui fazer o mestrado sobre isso, com o enfoque na educação popular[...]". (Docente 4)

“Em 2000, eu fui trabalhar na Atenção Primária e eu fiquei até 2010 na Saúde da Família, que ainda estava começando o Programa de Saúde da Família no município de São Paulo, que era o projeto Qualis[...]". (Docente 5)

“Eu só trabalhei no SUS, e com certeza essa [prática profissional] é guia de todo meu pensar como uma profissional de saúde coletiva [...] e agora na docência na atenção primária[...]". (Docente 1)

A prática profissional no SUS construiu o pertencimento que influencia as docentes terapeutas ocupacionais a promoverem a formação de futuros terapeutas ocupacionais para APS. Nesse tocante, percebemos que a trajetória de formação profissional e acadêmica das docentes terapeutas ocupacionais na APS demonstra que a terapia ocupacional vem promovendo diálogos com esse campo desde o processo da Reforma Sanitária até os dias atuais. Isso reforça a importância de sistematização das contribuições próprias dessa profissão para a APS, a fim de reconhecer suas trajetórias e colaborar com a formação de futuros terapeutas ocupacionais.

\section{As atividades de formação nos campos do ensino, pesquisa e extensão para a APS}

Cabe destacar que os Cursos de Terapia Ocupacional das instituições participantes dessa pesquisa apresentam aproximações com o campo da APS desde sua criação, inicialmente de maneira incipiente e, após as Diretrizes Curriculares de Terapia Ocupacional de $2002^{5}$, com maior inserção teórico-prática desse âmbito assistencial nos currículos. Isso é observado nos excertos a seguir:

“Eu entendo que, desde o período que eu entrei nesse curso (isso é 1986), a APS está colocada[...]". (Docente 7)

“A mudança do currículo [em 2008], que foi de acordo com as diretrizes de mudanças curriculares deu uma ênfase maior na Atenção Primária[...]". (Docente 3)

“Nossa IES já implantou seus cursos dentro do referencial das diretrizes curriculares [de 2002], já tínhamos a preocupação em formar as pessoas para o SUS e para a atenção primária, desde 2006, quando os cursos foram implantados[...]". (Docente 1)

"O curso começou em 2002, mas, acredito que em 2006 ou 2007. Nesse ano, foi criada a disciplina de Terapia Ocupacional em Atenção Básica, que passou a fazer parte, então como uma disciplina obrigatória[...]". (Docente 8)

"O ensino da APS enquanto um campo teórico, temos há muitos anos, como uma temática dentro do ensino da saúde pública, esse conteúdo era garantido, mesmo que minimamente. Como campo prático, é interessante saber que no início dos anos 2000 começaram algumas experiências na cidade de São Paulo, acopladas ao movimento do Qualis/PSF, que tinha como prioridade a Atenção Básica. E aí, abriu-se um campo de estágio (optativo) em São Paulo, que estava ligado à T.O. social, porque não tinha nenhum outro campo para se fazer um convênio[...]". (Docente 4)

Além das mudanças curriculares provocadas pelas Diretrizes Curriculares de Terapia Ocupacional de 2002, como relataram as docentes 3, 1 e 2, tivemos as falas das Docentes 7 e 4 que apontaram a APS como relevante para a área de terapia ocupacional, mesmo antes dessa indução, o que mobilizou fluxos que já permitiam a formação voltada para APS. 
Dessa maneira, na perspectiva do 'Ensino', Oliver et al. ${ }^{6}$ - ao discutirem a formação para APS a partir dos debates do grupo de trabalho sobre Formação do Terapeuta Ocupacional para APS, realizados durante o I Seminário Nacional de Terapia Ocupacional em APS, em outubro de 2011 -, atestaram um consenso de que os cursos têm gradativamente incorporado a formação na APS, embora com variações na forma e carga horária dedicadas ao campo. Essa tendência também é observada nos diferentes relatos:

"O curso é dividido por eixos específicos que são da terapia ocupacional e os eixos comuns que é o eixo o ser humano e sua dimensão biológica, o eixo do ser humano e sua inserção social e o eixo do Trabalho em Saúde (TS). A TS fala sobre território, insere o que é uma abordagem territorial, explica o que é SUS para os alunos. Depois no estágio em APS, trabalhamos bastante o específico [Terapia Ocupacional] nesse campo e eu tenho um enfoque da abordagem territorial e comunitária mais voltada para pessoas com deficiência[...]". (Docente 1)

"Com conteúdos teóricos e práticos já vinculados a alguma atuação do estudante na entrevista, na avaliação, na proposta de intervenção junto aos usuários da APS temos a disciplina específica [Terapia Ocupacional em Atenção Básica no terceiro ano], e tem outras disciplinas que estão organizados por ciclos de vida [...]". (Docente 8)

"No segundo ano os alunos vão para a Atenção Básica. Eles são divididos em quatro subgrupos e divididos em seis Unidades Básicas de Saúde ou Unidades de Saúde da Família. A gente tem privilegiado que sejam Unidades de Saúde da Família, esses alunos, eles são acompanhados no campo por um preceptor, que é um terapeuta ocupacional vinculado à rede de Atenção Básica, e aqui na universidade, eles recebem a supervisão de um facilitador, no caso sou eu, para fazer a reflexão sobre essa prática[...]". (Docente 3)

Essas diversas experiências nos possibilitam visualizar a construção das estratégias de intervenção e cuidado que estamos proporcionando na formação para atuação do terapeuta ocupacional nos serviços de APS 6 .

No campo da 'Pesquisa', observa-se a presença das docentes terapeutas ocupacionais em grupos de pesquisa que envolvem a APS, além da possibilidade do desenvolvimento de pesquisas da terapia ocupacional na APS por meio de Programa de Pós-Graduação.

"Dentro da pesquisa, estou como docente e pesquisadora de um grupo chamado Laboratório de Estudos e Pesquisas em Formação e Trabalho em Saúde, estamos realizando um estudo chamado de Redes de Cuidado em Saúde[...]". (Docente 1)

"Como aqui na IES temos o Programa de Pós-Graduação em Terapia Ocupacional (PPGTO), a Atenção Básica também está aberta para pesquisa no PPGTO[...]". (Docente 3)

"Participo de um grupo de pesquisa que aborda os contextos psicossociais e nele se contemplam as pesquisas na Atenção Básica[...]". (Docente 8)

Por outro lado, o PET - Saúde, mesmo sendo um dispositivo de reorientação da formação que privilegia os cenários de prática - muitas vezes, articulados institucionalmente, como campos da extensão de serviços à comunidade -, aparece nos relatos das docentes como uma estratégia importante para a realização de pesquisas no campo da APS.

"A pesquisa funciona muito em função dos projetos de extensão e também pelas Iniciações Científicas (IC). Eu tenho trabalhado com o PET/materno infantil, tenho feito pesquisas sobre essa clientela de mulheres, de gestantes e de crianças[...]". (Docente 2) 
Além disso, as docentes abordaram a necessidade de ampliar a participação em grupos de pesquisa, que envolvam a APS e a realização de pesquisas nesse contexto.

"Quanto à pesquisa: fazemos bem pouco. E isso, eu sempre falo com os alunos e faço a minha mea culpa, que é o quanto que a Terapia Ocupacional podia contribuir mais com produção científica, até para dizer, desse nosso lugar, da onde a gente está falando[...]". (Docente 12)

Como percebemos, há uma necessidade de ampliação na realização de pesquisas, e esse perfil tem experimentado mudanças com o aumento do número de cursos de terapia ocupacional e pesquisadores vinculados à pós-graduação e a grupos de pesquisa.

No campo da 'Extensão', os projetos apresentados foram bem diversos, e isso demonstra uma pluralidade quanto às contribuições da terapia ocupacional para APS nesse campo.

"A maior parte dos projetos de extensão [da APS] está voltada para a capacitação e a educação permanente dos profissionais[...]". (Docente 3)

“Na extensão, temos a Rede de Bem Estar e pegamos os casos mais necessitados de apoio do território para fazer um acompanhamento [...] Uma outra extensão, que se chama Baú de Histórias, trabalhamos com as crianças da sala de espera[...]". (Docente 2)

"Na Extensão, eu coordeno um projeto vinculado a um grupo de agentes comunitários[...]" . (Docente 8)

“Eu tenho um projeto de extensão que acontece na estratégia saúde da família do município, dentro da linha de cuidado materno-infantil[...]". (Docente 9)

Também foram citadas, no campo da Extensão, estratégias de formação para APS do Ministério da Saúde, como o PET-Saúde e o Ver-SUS. Essas estratégias de extensão possibilitam, aos estudantes de terapia ocupacional, o contato com alunos de outras formações e com o cotidiano dos serviços da APS ${ }^{6}$.

"Quando você tem o PET e tem uma política que claramente coloca a atenção básica no centro do interesse e como uma estratégia importante para desenvolver o próprio SUS [...]". (Docente 7)

"Vários deles [alunos] conseguimos fazer com que participassem do Ver-SUS durante a formação [...]". (Docente 9)

É importante destacar que o PET-Saúde, na perspectiva de Fonsêca e Junqueira ${ }^{18}$, contribui para potencializar, nos estudantes, a compreensão compartilhada de problemáticas e necessidades de saúde, bem como o cuidado de pessoas e famílias no nível local de cada território.

\section{Metodologias de ensino-aprendizagem}

Atualmente, na área da saúde, surgem questionamentos sobre as metodologias de ensino e sobre o perfil da formação do profissional, sobretudo, com inquietações relativas à tendência de especialização precoce e ao ensino caracterizado por parâmetros curriculares baseados no modelo biomédico ${ }^{19}$.

Diante desse contexto, as docentes expressaram diferentes aspectos sobre as metodologias de ensino-aprendizagem com o foco na formação do estudante de terapia ocupacional para APS, tais como o uso de: Metodologias Ativas; Metodologia "Tradicional" e Ensino Baseado em Evidências de Artigos Científicos. Além disso, também houve crítica à universalização do modelo de metodologia ativa e construtivista como uma tendência universal para a formação de profissionais de saúde na APS.

As 'metodologias ativas' utilizam a problematização como estratégia de ensino-aprendizagem, com o objetivo de alcançar e motivar o estudante, pois, diante do problema, ele se detém, examina, reflete, 
relaciona a sua história e passa a ressignificar suas descobertas ${ }^{19}$. Esse tipo de estratégia é exposto pelas docentes.

“Do ponto de vista metodológico temos tido como referencial não só para o ensino da Atenção Primária, mas para o curso como um todo, as metodologias ativas de ensinoaprendizagem[...]". (Docente 3)

“Trabalhamos com metodologias ativas, o propósito é que o aluno vá descobrindo, damos o conteúdo teórico, ele vai para a prática vivenciar o que ele viu na teoria, só que essa vivência é muito maior, porque conseguimos explorar muito mais, por que estamos em campo[...]". (Docente 2)

Por outro lado, as IES que não adotaram os pressupostos pedagógicos inovadores oficiais (a partir do Pró-Saúde, por exemplo) passaram a ser chamadas de 'tradicionais'. E o não falar, não escrever ou não defender as possíveis vantagens das metodologias ativas passou a ser quase um delito no campo da formação de profissionais de saúde ${ }^{20}$. Esse aspecto se repete no discurso exposto abaixo:

"As aulas são planejadas dentro de uma metodologia mais tradicional. Porém, eu gosto bastante de utilizar metodologias ativas. Não tem como modificar e dizer que "eu aplico metodologias ativas", por que não é uma proposta da Universidade. Para eu aplicar metodologias ativas, de forma geral, eu teria que ter uma mudança não só no meu planejamento, mas na estrutura de aula, da turma e da Universidade[...]". (Docente 9)

Temos, também, docentes que relataram utilizar diversas estratégias metodológicas na formação do estudante para a APS. Em relação ao aspecto "tradicional", esse ficou restrito a metodologia de lecionar aulas, como podemos observar na seguinte fala.

"Sempre abordamos vários tipos de metodologias, temos aula expositiva tradicional, onde o professor leva o conteúdo através de data show e slides, temos uma parte onde utilizamos a discussão de textos, fazemos debates, principalmente na parte de legislação, debatemos com os alunos a questão dos direitos que foram conquistados e o que é hoje cumprido ou vigente[...]". (Docente 10)

Uma outra maneira expressa pelas docentes foi 'o ensino baseado em evidências de artigos científicos'. Em relação a esse aspecto, entendemos que a contribuição do acúmulo teórico no campo da terapia ocupacional poderá provocar movimentos para a produção de cuidado com qualidade nos cotidianos de encontro entre terapeutas ocupacionais e a população na APS.

“Como, a atenção básica, é uma prática ainda muito recente para os terapeutas ocupacionais, buscamos sempre embasamento em artigos e aí depois tentamos identificar alguns pontos de ação dentro da prática [...]". (Docente 11)

"A nossa estratégia de aproximar da [APS] é a partir do uso que eles têm dos serviços e a partir de discussão de artigos científicos [...]". (Docente 12)

“Eu utilizo muito a articulação teórico-prática até pela questão da própria carga horária das disciplinas e do curso, elas serem bastante reduzidas [...]". (Docente 16)

“No estágio [deficiência física na APS] não damos nenhum texto. É a prática, tem que fazer. Na medida em que vamos fazendo o estágio, "Ah surgiu uma dúvida em relação a inclusão escolar", então vamos pegar uma discussão sobre inclusão escolar e vamos trazer[...]". (Docente 6) 
Diante dessas considerações das docentes, trazemos a contribuição de Bassi², que, ao discutir os aspectos referentes à formação e à prática do terapeuta ocupacional na APS, alegou que muitos profissionais da área passaram a remodelar o seu trabalho na APS por meio dos estudos e experiências acumuladas.

No entanto, entendemos que essa não pode ser a única maneira de se trabalhar a formação de terapeutas ocupacionais para APS. Do mesmo modo, como aborda Conterno ${ }^{20}$, ao 'criticar a universalização da metodologia ativa' como indispensável à formação dos profissionais de saúde, ao trazer a reflexão de que se está forjando um consenso sobre as metodologias ativas, como as únicas formas progressistas de se responder aos problemas na formação dos profissionais de saúde. Essa crítica é exposta pelo seguinte relato:

\footnotetext{
“Essa discussão sobre [metodologia de ensino aprendizagem] é bem cara para mim, porque na educação a forma de ensinar e de aprender é um debate antigo, mas atualmente o modelo "correto" tem que estar baseado na pedagogia construtivista e nas metodologias ativas. Faço essa discussão na minha tese e concluo que nesse modelo a figura do professor desaparece. Outros elementos compõem o cenário: tutor e preceptor, que devem intermediar o aprendizado. Não compartilho com a ideia da aprendizagem centrada na figura do aluno, excluindo o professor dessa relação. Não acredito que se o aluno tiver alguma orientação, a partir das suas necessidades/interesses, por si só ele aprenderá[...]". (Docente 15)
}

Dessa forma, é preciso cautela para que os processos formativos direcionados para APS não venham a fortalecer a lógica de um sistema de saúde de atendimento restrito a serviços de baixo custo, destinado à maioria da população, voltados mais às atitudes pessoais dos alunos e, menos, ao domínio do conhecimento já produzido 20 .

Nesse sentido, faz-se necessário, como apontou Conterno ${ }^{20}$, a discussão sobre as metodologias de ensino na formação do campo da saúde, visto que esse elemento é importante para a construção do SUS e para a qualidade do cuidado prestado pelos profissionais de saúde à população.

\section{Considerações finais}

Ao entrelaçar a trajetória docente, a formação nos campos do ensino, pesquisa e extensão, juntamente com a discussão das metodologias de ensino utilizadas para a formação de terapeutas ocupacionais para a APS, percebemos a potência que o campo da APS proporciona para a formação em terapia ocupacional. Entretanto, há a necessidade do desenvolvimento do núcleo profissional e interdisciplinar nesse contexto, acompanhado do aumento do número de profissionais envolvidos na pesquisa, na prática profissional e no ensino na APS.

Nesse sentido, é importante que o estudante experimente na sua formação: a riqueza da trajetória dos docentes, a formação nos eixos do ensino, pesquisa e extensão, e que vivencie práticas que exijam dele a aprendizagem de estratégias de atuação e cuidado resolutivas e que permita a comunicação com o outro no lugar dos serviços e das práticas na APS.

Mesmo sendo representativo o recorte empírico do estudo, por o estado de São Paulo possuir o maior número de cursos do país, temos esses achados circunscritos à realidade paulista; ao passo que enxergamos as riquezas e problemáticas nas diversidades das formações realizadas pelo Brasil, o que deve ser fonte de investigação de novas pesquisas sobre formação em terapia ocupacional para o trabalho interprofissional nos contextos do SUS.

\section{Colaboradores}

Rodrigo Alves dos Santos Silva e Fátima Corrêa Oliver participaram, igualmente, de todas as etapas de elaboração do artigo. 


\section{Referências}

1. Soares LBT. Terapia ocupacional: lógica do capital ou do trabalho? São Paulo: Hucitec; 1991.

2. Bassi BGC. Terapia ocupacional na atenção básica à saúde no município de São Carlos: um enfoque nas pessoas com deficiência e nas pessoas com sofrimento mental [dissertação]. São Carlos (SP): Universidade Federal de São Carlos; 2012.

3. Soares LBT. História da terapia ocupacional. In: Cavalcanti A, Galvão G, organizadoras. Terapia ocupacional: fundamentação \& prática. Rio de Janeiro: Koogan; 2007. p. 3-9.

4. Emmel MLG, Cruz DMC, Figueiredo MO. An historical overview of the development of occupational therapy educational institutions in Brazil. South African J Occup Ther. 2015; 45(2):63-7.

5. Ministério da Educação e Cultura (BR). Resolução CNE/CES, n 6, de 19 de fevereiro 2002. Instituiu as Diretrizes Curriculares Nacionais do Curso de Graduação em Terapia Ocupacional. Brasília (DF): Ministério da Educação; 2002.

6. Oliver FC, Pimentel A, Uchôa-Figueiredo LR, Nicolau SM. Formação do terapeuta ocupacional para o trabalho na Atenção Primária à Saúde (APS): contribuições para o debate. Cad Ter Ocup UFSCar. 2012; 20(3):327-40.

7. Oliveira RH. Terapia ocupacional na estratégia saúde da família: reflexões e perspectivas. In: Bourget MMM, organizadora. Estratégia Saúde da Família: a experiência da equipe de reabilitação. São Paulo: Martinari; 2008. p. 78-96.

8. Sampieri RH, Collado CF, Lucio PB. Metodologia de pesquisa. São Paulo: McGraw-Hill; 2013.

9. Palm RCM. Catálogo latinoamericano de asociaciones, carreras y postgrados de terapia ocupacional. Curitiba: CLATO; 2012.

10. Ministério da Educação e Cultura (BR). Portal do e-MEC [citado 29 Jan 2016].

Disponível em: http://emec.mec.gov.br.

11. Bardin L. Análise de conteúdo. São Paulo: Edições 70; 2011.

12. Ministério da Saúde (BR). Conselho Nacional de Saúde. Resolução n 466, de 12 de Dezembro de 2012. Aprova as diretrizes e normas regulamentadoras de pesquisas envolvendo seres humanos. Brasília (DF): Conselho Nacional de Saúde; 2012.

13. Ministério da Educação e Cultura (BR). Lei n 9.394, de 20 de dezembro de 1996. Lei de Diretrizes e Bases da Educação Nacional LDBEN/1996. Brasília (DF): Ministério da Educação; 1996.

14. Nicolau SM. Grupos na atenção básica: enraizar-se em uma comunidade. In: Maximino V, Liberman F, organizadoras. Grupos e terapia ocupacional: formação, pesquisa e ações. São Paulo: Summus; 2015. p. 264-74.

15. Oliver FC, Tissi MC, Aoki M, Vargem EF, Ferreira, TG. Participação e exercício de direitos de pessoas com deficiência: análise de um grupo de convivência em uma experiência comunitária. Interface (Botucatu). 2004; 8(15):275-88.

16. Oliver FC, Almeida MC. Reabilitação baseada na comunidade. In: Cavalcanti A, Galvão G, organizadoras. Terapia ocupacional: fundamentação \& prática. Rio de Janeiro: Koogan; 2007. p. 125-32.

17. Lancetti A, Gouvêa IGC. Projeto qualis: a revolução interrompida. In: Santos L, Andrade LOM, organizadores. Saúde Pública: meu amor. Campinas: Saberes; 2013. p. 119-27.

18. Fonsêca GS, Junqueira SR. Programa de educação pelo trabalho para a saúde: ressignificando a formação dos profissionais de saúde. Curitiba: Appris; 2014. 
19. Mitre SM, Batista RS, Girardi-de-Mendonça JM, Morais-Pinto NM, Meirelles $C A B$, Pinto-Porto $C$, et al. Metodologias ativas de ensino-aprendizagem na formação profissional em saúde: debates atuais. Cienc Saude Colet. 2008; 13(Supl 2):2133-44.

20. Conterno SFR. Pressupostos pedagógicos das atuais propostas de formação superior em saúde no Brasil: origens históricas e fundamentos teóricos [tese]. São Carlos (SP): Universidade Federal de São Carlos; 2013.

Silva RAS, Oliver FC. Trayectoria docente y la formación de terapeutas ocupacionales para la atención primaria a la salud. Interface (Botucatu). 2017; 21(62):661-73.

El objetivo fue identificar y analizar la trayectoria docente y la formación de terapeutas ocupacionales para la Atención Primaria a la Salud (APS) en el estado de São Paulo, Brasil. Encuesta de abordaje cualitativo por medio de la realización de entrevistas con 17 docentes de terapia ocupacional. Los datos se categorizaron en dos temas: 1) La trayectoria docente se identificó con la APS por medio de experiencias de formación, de práctica profesional y de anhelos de cambios para las posibilidades extramuros de actuación territorial y comunitaria de la terapia ocupacional. 2) las docentes señalaron la realización de la formación para APS en los cursos por medio de diferentes estrategias de enseñanza, investigación y extensión. La trayectoria docente en la APS y el aprendizaje teórico-práctico debe valorizarse en la formación de terapeutas ocupacionales para APS.

Palabras clave: Terapia ocupacional. Formación de profesionales de salud. Trabajo en salud. Atención primaria a la salud. Sistema Brasileño de Salud. 
